\title{
17
}

\section{Conclusion: Real World Learning- Researching and Co-constructing Working Definitions for Curriculum Development and Pedagogy}

\author{
Dawn A. Morley
}

\section{Introduction}

During 2019, the lead editor for an open-access edited collection 'Applied pedagogy for higher education. Real world learning and innovation across the curriculum' consulted with 15 groups of authors whose chapters had been selected for submission. The authors and case studies presented expertise on applied pedagogies from a variety of disciplines, and higher education specialisms, from eight universities from across the UK.

Overall, the research study followed the methodology of concept mapping by engaging authors in a collaborative exercise to co-construct the emerging pedagogic issue of 'real world learning' within their own sectors. Previous studies (Ornellas, Falkner, \& Stalbrandt, 2019) used qualitative methodology to establish a theoretical framework to build on authentic learning for employability, but the choice of concept mapping for this study hoped to address two purposes. The first was to facilitate a

\section{A. Morley (殴)}

School of Sport, Health and Social Sciences, Solent University, Southampton, UK 
deep and immersive critique of authors' real world learning approaches for the purposes of thematic analysis. The second gave authors a visual route map of their own reflections on real world learning to assist them with the writing of their own chapters.

Concept mapping is a 'graphic organisational technique' designed to help individuals (and groups) explain and explore their knowledge and understanding of a topic...

1. The concepts that an individual deems important in illustrating their personal understanding of a topic are placed in text boxes and arranged hierarchically...

2. Concepts are then linked with arrows that are annotated with 'linking statements' to explain the nature of the link

3. Concepts may be listed only once, but any number of links may be made between any number of concepts at any number of conceptual links. (Hay \& Kinchin, 2006, p. 129)

The authors were viewed as experts but were also all working within changing higher education environments and could therefore reflect from a wider, rich and socially constructed perspective. For the purposes of this study, the research was concerned with "clarifying, validating or building a theory" (Gray, 2017, p. 3) of real world learning for the explicit intention of being of use in the design of curriculum and pedagogy within higher education. The first purpose of its usefulness was to give authors a tangible framework of their own definition of real world learning in order to build the narrative of their chapters.

\section{Methodology}

For the purposes of this study, authors' discussions of the concept of real world learning and a description of their own educational context and situation occurred in their chapter groups and through concept mapping. This followed a technique of enhancing the construction of concept maps through a facilitated narrative reflection between the lead editor and authors (Kinchin et al., 2018). The resultant visual "networked" concept 
maps, where concepts link in multiple directions (Hay \& Kinchin, 2006) from each author group, demonstrated the complexity of the concept of real world learning. These are included in the relevant, associated chapters.

Following focus groups with 15 groups of authors the transcriptions of discussions on real world learning were thematically analysed using Nvivo 11.

\section{Real World Learning Analysis}

Although three main themes emerged from the data analysis, all authors began by providing examples of what they defined as real world learning. Some universities had already gained advanced expertise on negotiated work-based learning frameworks (Chap. 2) with the majority of authors naming overt initiatives within the curriculum where students were prepared for employment by being exposed to the world of work through, for example, placements (Chap. 7). Others named pedagogies that enhanced skills which were also seen as useful to the workplace, for example, innovative pedagogies (Chap. 12) and project-based learning (Chap. 8). At the early stages of discussion alternative approaches to learning were mooted. These included better use of the online environment (Chaps. 15 and 16) and less traditional access routes to real world learning such as the volunteering opportunities discussed in Chap. 5 through civic engagement (Chap. 4) as well as greater use of students' own cocreation of the curriculum (Chap. 3).

I think rooting it in these ideas of co creation is one of the ways because that's giving students ownership of the design of whatever they're doingprojects scenario or what have you-... it's still not real world it's sort of real world-esque.

As authors reached a deeper level of collaborative discussion between themselves and the researcher, more nuanced themes began to be discussed and, when thematically analysed, produced the three themes of fidelity, individuality and mutuality. 


\section{Theme One: Fidelity}

Authors believed that creating a situated learning context, that replicated as close as possible the authentic world of work, could manifest itself both in curriculum design and the manner of learning. "Without the context ... the risk is students' learning is quite fragmented" and "if you're too abstract, and talk about theory, you don't get the context around it".

As a result of real world learning's fidelity to simulate, replicate or exist in authentic work settings, authors identified the close association of students developing employability skills with this type of situated learning. Simply students can "increase job prospects, employee relationships and networking" but many authors felt that this employability link was much more subtle and required deeper development to be effective on students' work readiness. Authors identified the development of identities and attributes, as opposed to simply a set of skills, that started at the beginning of the degree course building work readiness, as well as theoretical knowledge, as learning progressed

it isn't just about university as a factory for employability. It is about the person, it's about rethinking, well it's just trying to do a lot more within the university framework.

Exposing students to situations that they will meet again in their professional lives starts to build confidence as students gain tangible proof of their abilities.

'I might have a degree in the theory behind this, but I have run my own event.' What it's doing is, it's opening more doors.

Students begin to appreciate the holistic nature of employment where attributes and skills mix and blend dependent on the situation. Theory is enhanced by a foundation of soft skills that employers are increasingly expected to have been developed at university. To achieve this, authors identified a need for a repositioning of the employer-university relationship where there is closer communication on what is expected of 
graduates and how this can be achieved through the course. Fidelity needs to be co-constructed by a partnership of all three so the end point, when students leave university, is not too late to address the employers' needs.

employers always complain that they get these graduates who have got all this knowledge, but they don't know how to function in the workplace. And they don't prepare their students for the workplace, and I think perhaps, having this real world learning maybe lowers that risk for the employer.

This greater building of a collaborative partnership is supported in the study by Ornellas et al. (2019).

It was believed that learning with greater fidelity was an element of the curriculum that could be simplified or made more complex according to the students or the focus of the learning.

Fidelity is how you can validate against the real world. Verisimilitude is an area of fidelity. It's more about how you perceive the real world, how you perceive what you're doing to correspond to the real world, rather than the actual.

Authors argued that students could begin their studies with low fidelity design and pedagogy, for example, the use of case studies introducing them to the real world context. In order to avoid a "double switch off" academics need to be attuned to examples that will engage students. Following this, employability skills can be grown through medium fidelity examples, such as simulation and gaming (Chap. 9), to full immersion into the authentic context of work where students learn through live briefs or find themselves fully participating in the work environment at university and beyond. A greater level of learning control is presented lower in the fidelity spectrum which may be appropriate for learners naive to the work environment, for the lecturer to take a particular learning focus or when an alternative problem base is needed for the more experienced practitioner. 
you could argue that simulations might be a better aid to learning than something that's totally real world because it helps to simplify things, make it slightly more abstract than real world that takes you part way to that abstract conceptualisation that you need to fully understand a problem or situation.

Most significantly, the level of immersion impacted the affective engagement of students. What was viewed as the ideal trajectory from low to high fidelity learning situations increased not only the novelty of the learning, but students were stretched to a more expansive type of learning — deeper and more problem-based synonymous with "graduateness" (Holbery, Morley, \& Mitchell, 2019).

High fidelity learning was associated with greater risk, "there is risk, there is consequence, there's responsibility" and mistakability-a concept spoken about by many authors as a powerful way of students learning from their noncritical mistakes as students are situated at university rather than the real world itself, "And if they fell over, then it would be a poor mark and a learning experience with feedback, which you don't get later". Taking a real world learning approach gives "students a safe space to fail. They need to learn to fail and understand why they've failed, without additional pressure of they've just cost some business some money".

In turn, students have the potential to develop resilience and better preparation for employment by engaging attributes, such as leadership, critical thinking and collaborative working — "those won't develop, unless [students] are challenged, but what goes beyond ... a traditional, safe, HE environment". In effect, students' real world learning scaffolds them to reach their potential and the incremental building of this experience, reflected in Bruner's spiral curriculum (1960), continues to integrate an ongoing tension of personal achievement into the curriculum.

[Students] are on the periphery of a community, and they've got access into it. But they're meant to be a little bit grittier and a bit more asking questions. It's giving students permission to do that.

The balance of fidelity against academic content, for example, student participation in a complex business strategy game with the 
understanding of business theory, was important so students' clarification of their learning remained explicit. Authors also recognised that academics must be cognisant of the time to step in to rescue projects, or how much to offer students in the first instance, so the quality and timing of delivery were not compromised.

if there's too much fidelity, [that is] it represents the thousands of decisions you can make-a student wouldn't see the wood for the trees. You need to have simplification of reality which is complex enough to make those causal connections, but not too complicated that they can't do that.

Fidelity was enhanced by structures and pedagogy that increased students' awareness of their learning. Having the ability to reflect and articulate authentic learning experiences was important (Ornellas et al., 2019) as was the careful connection of the fidelity learning experience through the curriculum to an end point such as real-life practice or assessment (Morley, Bettles, \& Derham, 2019). It was possible to implement fidelity through all stages of the curriculum, but notable comment was made by authors on the importance of introducing an authentic assessment brief that used students' time purposely towards real world attributes and identities. Emphasis moved away from the confines of traditional summative assessment to one where the process of assessment was paramount, and it was important that the element of risk had no effect on the credit bearing of the course and students' ability to meet learning outcomes.

Authentic assessment, explored more fully in Chap. 14, had two purposes of creating opportunities for ongoing and longitudinal feedback that replicated that of the workplace "it's being able to recognise feedback and delays between decisions and actions, consequences" but also started to create a culture of self-regulation. With multiple and ongoing assessment points, students prioritised feedforward to their next assessment and had a greater awareness of their individual, ipsative development (Hughes, 2011, 2014). Authors advocated assessment methods that both cultivated success, irrespective of the starting point, but with enough room for the acknowledgement and extension of a priori knowledge. Students were more likely to transition from simple, single loop learning to more complex double loop solutions (Argyris \& Schon, 1974) as they 
could envisage the wider scope of their assessments. Again, assessments that were associated with greater prestige or risk were more likely to promote the affective engagement of students.

you're going to be doing things like generating assignment, which is real world, which could have been written for the outside world, rather than the sort of stuff that you would churn out for your A-levels just to get a grade.

In a "first steps" approach to real world assessment authors were more likely to use multi-faceted and innovative approaches to assessment, such as peer review and assessment, that recognised and reflected the links to the world of work. Learning technology was used significantly to enhance the fidelity of the assessment, feedback and the situation of the learning itself as presented in Chaps. 12, 15, and 16.

\section{Theme Two: Individuality}

Authors emphasised the individuality of students' personal trajectories as they travelled through higher education and the individuality of students' real world constructions where "they don't necessarily grasp how everything could make a difference to their own journey". Authors highlighted differences in age, experience of work and study, outside commitments and levels of confidence yet felt that students were often infantilised and "historically, is just solve it-treat everybody like they're the same, actually the same shape and size". Students developed at different stages necessitating a pedagogy that differentiated and built on students' individual experience "to do with personal development, as much as sort of professional pedagogy".

if you're going to make it real world, everybody's different. Everybody's come from a different place, and they might be heading in a different direction. And you've got enough scope, to be able to calibrate what you're doing to enhance that. 
Authors offered different stories of being part of the individual, transformational development of students. This was further enhanced when students' needs were considered holistically, and students were encouraged to develop an instinct for lifelong learning and preparation for employment going forward.

It's all going to be preparing them for work that doesn't exist now. So, what is it about real-world learning that's really going to enable them to leave confident and resilient ...?

The pedagogic theory that enhances real world learning therefore takes an individual, developmental ethos "it's almost as if you're taking a lot of the approaches, practices, philosophical underpinnings, and power relationships for andragogical university education and implanting it in a more traditional pedagogic environment". It is the antithesis of the shortterm immediacy that dominates traditional higher education, "things are changing over time and it's ongoing. That's what some students embrace, but others don't necessarily like that idea, they want things to be terminal" and builds on the work of theorists such as Kolb (1984), Dewey (1938) and Knowles, Holton and Swanson (2005). Real world learning requires a different mindset for longitudinal development that projects past students' university experience, rather than the achievement of shortterm goals and traditional, linear learning.

we can provide the support, but they have to be the people who kind of go away and make the connections between all the different things that help them step through. One of the things they don't do, is they don't saturate themselves with inputs.

Those authors running degree apprenticeship programmes (Chap. 11), as opposed to traditional degrees, noted the difference in student experience and how it impacted their learning. The differentiation within the student body meant that a pedagogy needed to be used that drew on the student experience as a starting point and allowed for these differences. 
[Students] need to be in a place where they can be reflective practitioners, they can be agile, they can be critical decision makers, so, it's pulling upon, I think probably just that agile element that we see from our realworld students.

Networking, (Chap. 3) and mentoring (Chap. 11 in the context of degree apprenticeships) were significant employability skills highlighted by authors but ones not naturally accessible to all students.

giving [students] the opportunity to network and establish contacts within that field, because it is so difficult to generate a career immediately coming out of an academic setting ... what we try to encourage the students to understand is that every time you're in a new situation, you're exposing yourself to a new group of people [and] to make everything count.

Student mentorship for employment trod a fine balance between encouragement and control that real world learning was trying to overcome.

As with leading more authentic assessments, authors articulated strategies where students' own individual development was made explicit and clear to them.

what we try and do behind it is to support them in mapping what they're doing. So, we see a lot of students that leave our programmes that don't necessarily capture everything that they've done over their time, they don't see the relevance of it. But the moment you sit down with them and say, 'well, you did this, you ran this particular event, which incorporated leadership, which incorporated management, the commitment, that control.' 'Oh, yeah, I didn't think about that. I just saw myself as running an event.' So, it's encouraging people from what we see at the start, to when we get to the end point. What does their journey look like? And how have they showed themselves as individuals to get that end goal?

This was supported by pedagogies that promoted "student agency, making decisions, wiser students, autonomy, motivation, curiosity”. Real time feedback from a range of facilitators, not just academics, strengthened the learning connections that students may miss in the present and 
"the real world element that they should see that that they're taking it forward into something else". Opportunities for students to reflect on their learning, presented in greater detail in Chap. 13 and interspersed throughout the chapters, allowed them to attend to their learning more instead of being hurried through imposed teaching schedules.

I think that's one of the reasons why the assessment based on reflection is important, rather than performance. Because they might crash and burn, but they'll have learnt a lot from it. It's often easier to reflect on what went wrong, than what went right.

Individuality also encompassed giving students choice over critical paths within degrees, and when students had greater opportunity to make assessment more personal to their interests, culture and needs, their motivation and enthusiasm were increased.

\section{Theme Three: Mutuality}

Mutuality involves a greater collegiality between student and facilitator-the facilitator could be either internal or external to the university including alumni and peer students themselves. In some instances, this created a flattening of the traditional power dynamics between student and academic. In the opinion of authors, the loosening of these boundaries allowed students the opportunity for the co-creation of new knowledge, a greater voice and the development of confidence while speaking to other professionals, usually with more experience. Through the proximity to real world practitioners, students learnt at first-hand about professional responsibility, "in the film industry, it's about daylight. So, you've got to be there early, you've got to be there on time, you've got to be unpacked and ready to go" and students "get real exposure on how to communicate with those people". Working with external experts allowed students a vicarious route into real world practice and access to the "war stories" and experience of current practitioners. 
it should be an opportunity to learn from people who have been where the students are heading for or might be heading for. It's a way to get insights and learn by doing and learn from people who have expertise.

Mutuality was defined differently by authors depending on their experience within higher education teaching. An influence was the introduction of degree apprenticeships and the perceived stronger relationship between student, higher education provider and the workplace facilitator that has resulted.

the direction should be two way, we should be upskilling industry in terms of knowledge exchange, but the practicality of what the students learn out in the field should be coming back and informing theory. There should be that two-way process.

Authors reflected on the need for three-way partnerships as a conduit for students attaining a real world education. Increasingly, external partners were taking more diverse roles in higher education from the more traditional workplace mentor and assessor to being actively involved in course design.

we're here to service the needs of the business region, so, it's working with them and actually doing that. And that's where we have to be agile, we have to be connected to the customer that we serve, and the customer being the industry that we provide the talent to help gear that and make it happen.

Authors noted that engaging students in "mutuality" came with increased responsibility. Academics had to ensure support systems were in place, regulatory commitments were met and students gained appropriate experience to both their future professional and personal needs. Authors also commented on the challenge mutuality could bring to the workplace.

we have got apprentices that have grown so much in themselves confidence wise, knowledge wise, and they're now starting to question the capability, the management style, the quality and level of decision making that's happening above them through the organisation. So, in many ways for 
organisations adopting this real-world learning approach and looking at nurturing talent and using these apprentice opportunities, you're almost creating a great wealth for energy within an organisation. But unless it's driven from the top-down, this can be quite challenging from a change model perspective.

With the increased acceptability of outsourcing teaching, learning strategies were heightened and more clearly thought through on how to successfully bridge the divide of students working and learning in different settings. Connecting theory and practice is a recognised and perennial issue within higher education learning (Evans, Guile, \& Harris, 2009) and many authors commented upon this and saw it as important to the success of real world learning. The interdependency between the two was either enhanced inductively when students were in practice first, and then had a foundation of experience to base their theory around, or deductively when theory was taught first and practice applied later.

Authors talked of several learning strategies that encompassed mutuality. Peer learning was a popular choice where students worked with each other's individual abilities to build teams with the possibility of extending this to assess group dynamics.

And when students receive their grades, they will receive their grades from the tutor, and we will say overall as a group, you've got a B. Now go away, peer assess each other. So, the students then can compare the two, and see, okay, so my tutor saw this, but my colleagues didn't: what am I doing differently, and vice versa.

\section{Conclusion}

Real world learning focuses on developing attributes towards employability and lifelong learning - those mentioned were challenge, cultural competence, competition, leadership and professional networking - not usually associated with traditional university education. It reflects "shifting expectations about what universities are for in the last ten, fifteen, twenty years". Instead of focusing on the traditional learning methods 
that systematically build knowledge or community, real world learning looks for impact that can be carried and developed by the individual student as they journey through university, and then into employment and lifelong learning. Ornellas et al. (2019) argue for a

broadened notion of authentic learning [that] incorporates not only the epistemological dimension - what students are expected to know and be able to do-but also the ontological—who students are becoming and learning to be.

The difficulties of the integration of employability skills, and the disjunction within the curriculum experienced by students, could go some way to be resolved through a greater real world learning approach.

You're taking something and you're recalibrating it-it's not totally different ... there's a subtle but really important change of direction and purpose for it.

There were many suggestions as to the scale of a real world learning approach "we're talking about effectively, totally reengineering your whole curriculum. So that pretty much every experience the student takes part in has some real world and focus" and the issues of integration "so it's not an add on" and an "undercut for the local industry". The study found that most authors were able to isolate different areas of curriculum design and pedagogies that took a real world learning approach suggesting that, irrespective of discipline, this emerging ethos has resonance across the higher education sector.

Some universities, recognising a difference in their real world ideology and approach, used this as a competitive advantage to attract students. Others realised that strategies, such as the creation of internal companies for placements presented in Chap. 7 , increased control and the ability to offer work experience to many students in disciplines where finding placement experience was challenging.

From speaking to authors, all active practitioners and passionate advocates of real world learning, and "high investment education", the 
discussed real world learning strategy takes time, effort and considerable creativity.

Real world learning is a lot harder to set up than just writing a lecture you write a lecture you do some powerpoint slides—job done. Real world learning takes a lot more thought ...

As well as the efforts of individuals and teams, it was recognised that the commitment required for real world learning may be challenging to adopt with the "need to break down those separate silos" and "... to seriously start connecting bits of ... universities together in a way that can help create something different, new, and which is going to take HE to the next level".

It was anticipated that "[blurring] of the power relationship" may draw resistance from academics and the nuances of "the lecturer [being] there to facilitate the learning rather than deliver the content". Many academics are either uncomfortable or unpractised adopting a coaching style with students so suggestions of broadening the net of facilitators to ones within industry, alumni networks and retired professionals could also expose students to the valuable experience of different styles of support and management.

you need the confident facilitator for that, and not everyone will feel comfortable. And not all the students will feel comfortable either, which is a challenge, convincing the students that this could be a benefit to them-if they're going to feel exposed or vulnerable

Many authors had been frustrated in persuading quality processes at universities to take a more open approach to learning outside of the curriculum when, for example, sports placements were available. An allowance for greater flexibility with deadlines and enrolment due to students' real work commitments were concerns that "the quality processes that we have don't impede these initiatives ... we certainly would need to ensure that we have got proper quality procedures that address work-based learning initiatives". 
A factor not mentioned by authors was the move in higher education towards a greater quantitative measurement of student course evaluation. Traditionally student evaluation has prioritised the "fire alarm function" (Edstrom, 2008) where audit, the measurement of the "here and now" of teaching quality, has taken precedence over examining how evaluation can be used as a catalyst for future development. Taking a more reflective approach to evaluation encourages students to be "more considered, they interrogate their own engagement in the learning context, and they are more likely to demonstrate reconstructive thought" (Ryan, 2015, p. 1142). Nestel et al. (2012, p. 9) believe that the use of alternative methods could contribute to an "evaluation culture" where students felt "valued, respected and heard". A sense of engagement in the moment of the evaluation, and the encouragement of greater ownership with fellow students, seems possible using the professional networks discussed in Chap. 3 which provides suggestions for collaborative discussion between student and academic more in keeping with a real world learning approach.

Overall, authors spoke with enthusiasm of their real world learning initiatives which had motivated their students but also inspired their own professional practice.

the students are challenged a lot of the times - the activities can be difficult for them, but I think they do enjoy the fact that they're different and all get some other things from it. From a staff perspective it's nice to do different things rather than just have four thousand-word reports to mark across every module ... it just brings a bit of variety into it.

Most importantly, it charged both staff and students with an educational approach that goes beyond the university experience and one that is more pertinent to students' employability requirements. It instils a learning ethos that "[tries] to dig deeper and wider perhaps than some of us have courage to do" and "creating these lifelong learners so it's not just about the skills it is about a passion for learning too ... they're motivated because they enjoy it ... it has the ability to get people hooked into learning". 
Chapter authors demonstrated a multiplicity of ways that the three themes of the research could be integrated into curriculum design and pedagogy. By the discovery of alternative routes through the traditional higher education systems (Chaps. 2, 4, 5, 10, and 11) and a re-emphasis on the pedagogies of what authors termed real world learning (Chaps. 3, 7-9, and 12-16) authors saw at first hand the benefits of more carefully considered curriculum that addressed changing student needs.

\section{References}

Argyris, C., \& Schon, D. (1974). Theory in practice: Increasing professional effectiveness. San Francisco: Jossey Bass.

Bruner, J. (1960). The process of education. Cambridge, MA: The President and Fellows of Harvard College.

Dewey, J. (1938). Experience and education. London: Collier-Macmillan Ltd.

Edstrom, K. (2008). Doing course evaluation as if learning matters most. Higher Education Research and Development, 27(2), 95-106.

Evans, K., Guile, D., \& Harris, J. (2009). Putting knowledge to work: Integrating work-based and subject-based knowledge in intermediate level qualifications and workforce up skilling. Retrieved from https://thecet.org/wp-content/ uploads/2018/10/Book-of-Exemplars.pdf

Gray, D. E. (2017). Doing research in the real world (4th Kindle ed.). London: Sage Publications.

Hay, D., \& Kinchin, I. (2006). Using concept maps to reveal conceptual typologies. Education and Training, 48(2/3), 127-142.

Holbery, N., Morley, D., \& Mitchell, J. (2019). Expansive learning. In D. Morley, K. Wilson, \& N. Holbery (Eds.), Facilitating learning in practice - A research based approach to challenges and solutions. Abingdon; New York: Routledge.

Hughes, G. (2011). Aiming for personal best: A case for introducing ipsative assessment in higher education. Studies in Higher Education, 36, 353-367.

Hughes, G. (2014). Ipsative assessment. Motivation through marking progress. Palgrave Macmillan.

Kinchin, I., Heron, M., Hosein, A., Lygo-Baker, S., Medland, E., Morley, D. A., \& Winstone, N. E. (2018). Researcher-led academic development. International Journal for Academic Development, 23(4), 339-354. https://doi. org/10.1080/1360144X.2018.1520111 
Knowles, M., Holton, I. E., \& Swanson, R. (2005). The adult learner (6th ed.). Elsevier.

Kolb, D. (1984). Experiential learning. Experience as the source of learning and development. Englewood Cliffs, NJ/London: Prentice Hall Inc.

Morley, D., Bettles, S., \& Derham, C. (2019). The exploration of students' learning gain following immersive simulation - The impact of feedback. Higher Education Pedagogies, 4(1), 368-384. https://doi.org/10.108 0/23752696.2019.1642123

Nestel, D., Ivkovic, A., Hill, R. A., Warrens, A. N., Paraskevas, P. A., McDonnell, J. A., \& Browne, C. (2012). Benefits and challenges of focus groups in the evaluation of a new graduate entry medical programme. Assessment and Evaluation in Higher Education, 37, 1-17.

Ornellas, A., Falkner, K., \& Stalbrandt, E. (2019). Enhancing graduates' employability skills through authentic learning approaches. Higher Education, Skills and Work-Based Learning, 9(1), 107-120. https://doi.org/10.1108/ HESWBL-04-2018-0049

Ryan, M. (2015). Framing student evaluations of university learning and teaching: Discursive strategies and textual outcomes. Assessment and Evaluation in Higher Education, 40(8), 1142-1158.

Open Access This chapter is licensed under the terms of the Creative Commons Attribution 4.0 International License (http://creativecommons.org/licenses/ by/4.0/), which permits use, sharing, adaptation, distribution and reproduction in any medium or format, as long as you give appropriate credit to the original author(s) and the source, provide a link to the Creative Commons licence and indicate if changes were made.

The images or other third party material in this chapter are included in the chapter's Creative Commons licence, unless indicated otherwise in a credit line to the material. If material is not included in the chapter's Creative Commons licence and your intended use is not permitted by statutory regulation or exceeds the permitted use, you will need to obtain permission directly from the copyright holder.

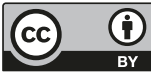

